\title{
Bundled payment model implementation in a hospital in Colombia: Challenges and key drivers of success
}

Juan P. Umaña, MD

Editor's Introduction-In the current era of quality and fiscal efficiency of health care, the United States Center for Medicare and Medicaid Services has introduced several proposals to explore alternate payment models to promote quality care. The efforts of the Center for Medicare and Medicaid Services have evolved with the inpatient prospective payment system and bundled payments following the introduction of the Medicare Access and CHIP Reauthorization Act in 2015 and proposed rule for coronary bypass grafting. ${ }^{1-3}$ This has set the stage for a strategic framework for hospitals and health systems to up their game by aligning their organizations around quality and protocolized care pathways.

In this issue of the Journal, Juan Umaña, provides us with some interesting lessons learned from an integrated clinical and administrative approach to bundled payments in Bogota, Columbia. A successful approach can be implemented by aligning a team effort, led by physicians, with contributions from hospital administration, insurance companies, and industry. Michael Mack furthers this dialogue through experiences with the Baylor Scott and White health system in Texas. Together, these contributions provide a barometer for those not already initiated with the growing imperative to align incentives around appropriate use, quality protocols, and fiscal responsibility.

\section{Vinay Badhwar, MD}

Hospitals and physicians have been under pressure to implement strategies to improve outcomes over the past 3 decades, with patient registries such as the Society of Thoracic Surgeons database playing a major role in continuous improvement initiatives that have made it possible to achieve mortality rates as low as $1 \%$ for coronary artery bypass grafting. ${ }^{4}$ These efforts have

\footnotetext{
From the Fundacion Cardioinfantil, Institute of Cardiology, Bogota; and University of El Rosario, Bogota, Colombia.

Received for publication June 9, 2019; revisions received Sept 1, 2019; accepted for publication Sept 22, 2019; available ahead of print Jan 24, 2020.

Address for reprints: Juan P. Umaña, MD, Fundacion Cardioinfantil, Institute of Cardiology, Calle 163A \# 13B-60, Edificio Fundadores 3er Piso, Bogota, Colombia

(E-mail: jpumana@cardioinfantil.org).

J Thorac Cardiovasc Surg 2020;159:1927-30

$0022-5223 / \$ 36.00$

Copyright (c) 2019 by The American Association for Thoracic Surgery

https://doi.org/10.1016/j.jtcvs.2019.09.192
}

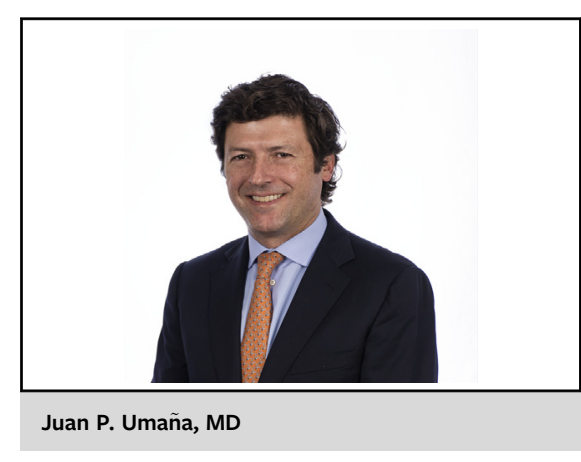

\begin{abstract}
CENTRAL MESSAGE
Alternative payment models are gaining ground in health care systems around the world. Physicians have to assume the leadership of interdisciplinary teams to guarantee the success of these models.
\end{abstract}

See Commentary on page 1931.

significantly benefited patients but have come at a substantial cost to systems across the world, where fee-for service models of reimbursement have prevailed. ${ }^{5}$ Health care costs have therefore skyrocketed, exceeding gross domestic product growth in some countries between 2016 and $2017,{ }^{6}$ making it imperative for governments to find mechanisms to curb spending while simultaneously trying to extend coverage to the majority of the population. This has led to a tendency to move health care reimbursement from fee-for-service to fee-for performance in the form of disease-specific payments, forcing institutions to engage in models that reinforce value-driven care. Value is defined as quality of patient care and service divided by total cost of care $(\mathrm{V}=\mathrm{Q}+\mathrm{S} / \$)^{7}$ It follows that if costs remain stable while quality and outcomes improve, value increases. The only way to implement this in real life is through engagement of all stakeholders involved in the care of our patients, by implementing integrated care pathways, decreasing the cost of new technology, and rationalizing its use through careful evaluation of the cost:benefit equation. This effort has to be led by physicians, who are ultimately in charge of health care spending. 


\section{SCOPE OF THE PROBLEM}

The Organization for Economic Co-operation and Development recently praised Colombia, the second-most populated country in South America, for introducing a bold health care reform in 1993, whereby all citizens, irrespective of their ability to pay, were entitled to comprehensive health care coverage. The system, known as Sistema General de Seguridad Social en Salud (SGSSS), covers $95 \%$ of the population and has led to major improvements in overall life expectancy (69 years in 1993 vs 74 years in 2015). As a consequence, health care spending increased from $5.4 \%$ of gross domestic product in 2004 to $7.2 \%$ in $2014,1.1 \%$ more than the average $6.1 \%$ for upper/middle-income countries worldwide. ${ }^{8,9}$

The SGSSS is funded through a combination of payroll contributions and general taxation, with $43 \%$ of affiliates contributing through their employers or self-employment and $48 \%$ being subsidized by the State through several taxation schemes. Funds are administered by a government entity that channels them to entidades promotoras de salud (EPS). These are private corporations that act as intermediaries between patients and health care providers (hospitals and clinics), much like health maintenance organizations in the United States.

\section{CURRENT CHALLENGES}

The system faces several challenges due to an aging population that resembles the pyramid of Organization for Economic Co-operation and Development economies, with a narrowing younger base and expanding numbers of older adults, as well as the rising incidence in noncommunicable diseases such as cardiovascular disease, cancer, and diabetes, which now account for $80 \%$ of the "high-cost account" within the SGSSS.

Among the most significant threats to the SGSSS are the rising costs of pharmaceuticals and devices. Pharmaceutical sales in Latin America were reported at USD $\$ 70$ billion in 2008 , which is relatively low compared with Asia ( $\$ 265$ billion), Europe ( $\$ 329$ billion), or North America (\$358 billion), but between 2008 and 2021, projected sales growth is significantly greater at $119 \%$, compared with $82 \%$ for Asia, $18 \%$ for Europe, and $22 \%$ for North America. ${ }^{10}$ In an effort to balance these market forces, in 2012 the government established the Institute for Evaluation of Technology in Health Care to support resource allocation decisions through health technology evaluations, as well as review and design of evidence-based clinical guidelines to improve the quality and efficiency of health care. To further this effort, in 2016 the Ministry of Health introduced a new reform that puts patients at the center of the System, by proposing the creation of pay-for-performance models based on integrated care pathways. Nonetheless, this new approach has yet to be implemented in a widespread fashion due to a limited health data infrastructure and lack of incentives for EPSs to improve quality of care without increasing costs. ${ }^{11}$ The Institute for Evaluation of Technology in Health Care currently lacks the mandate and the muscle to curtail the introduction of new technology, and the system doesn't have the capacity to update its coverage plans at a fast-enough pace to account for the rapidly rising cost caused by the use of novel medications and devices. This generates a cash flow deficit that is invariably shifted to the hospitals and clinics treating the patients.

To further complicate matters, fee-for service models incentivize the performance of more diagnostic and therapeutic procedures, as physicians and hospitals get reimbursed based on the volume of activity. This has generated a prevailing lack of trust between stakeholders (EPSs-hospitals-industry), working to protect their own interests first, as opposed to teaming up to solve the problem for the system as a whole. EPSs conceive multiple layers of obstacles and complex approval systems to decrease the number of high-complexity procedures performed to contain costs. They also refer patients to low-cost diagnostic centers irrespective of quality, fragmenting and delaying patient care. This increases the cost per episode of care (EOC) to the system, as referral centers are forced to repeat tests and treat patients late in their disease process, requiring more complex interventions with consequently longer hospital stays and a greater incidence of complications. In contrast, hospitals have to hire their own "armies" of auditors to counter EPS measures, driving up cost of care without a resulting impact on quality.

\section{CASE EXAMPLE OF SOLUTION}

At Fundacion Cardioinfantil-Institute of Cardiology, we believe that to break this cycle, strong leadership is required to bring EPSs, insurance companies, industry, and hospitals together to work as a team around the patients. As the leading cardiovascular institution in Colombia and given the knowledge we have of our cardiovascular population, we decided to explore alternative payment methods that could be applied to the Colombian health care system, to improve quality of care and guarantee financial sustainability.

In view of the scope of the project and the risks that such an undertaking could entail if not properly studied and implemented, we decided to design a pilot study with a trusted EPS that shared our vision and knowledge of cardiovascular patients. To create a mutually beneficial model, the 2 organizations created an interdisciplinary team to share and analyze information on cost and frequency of EOC for the patient population. Episodes of care included outpatient visits, noninvasive diagnostic tests, coronary angiography, percutaneous coronary interventions, coronary artery bypass grafting, isolated aortic valve replacement, mitral valve repair or replacement, aortic 
valve replacement or mitral valve repair or replacement in combination with coronary artery bypass grafting, electrophysiologic noninvasive or invasive diagnostic procedures, device implantations, and percutaneous ablation for atrial fibrillation, in-patient hospital stay (as needed), and postdischarge follow-up to 30 days. In the initial stages, there were inconsistencies on both ends, as the need for in-hospital EOC invariably appeared greater than what the insurance company had budgeted. In the end, data derived from the Fundacion CardioinfantilInstitute of Cardiology's institutional database and cardiovascular surgery patient registry pooled with that from the EPS's database were used to calculate a median number of patients that would be treated per month in the initial phase of the model. Two standard deviations above and below established the highs and lows that would later condition payments and trigger a reversal to fee-for service to protect the hospital from high-risk, outlier patients "breaking the bank."

The following step was to perform a financial analysis that included an exhaustive revision of the average market rates of all procedures to be included in the model. This was the most sensitive aspect of the negotiation, given the need to avoid up-front financial risk while ensuring competitive rates for physicians. We believed that the success of the program depended on their engagement and active participation and leadership.

Once the frequencies and payment schemes were defined, it was agreed to run a pilot study for a period of 6 months, during which the model would be validated without either party undertaking any financial risk. Payments involved a fixed monthly amount based on the previous 3 years of billing for the established frequency of EOC. Transcatheter aortic valve replacement, endovascular mitral valve repair, open and endovascular complex aortic procedures, and orthotopic heart transplantation were excluded. Only adult patients were included.

To guarantee the success of the pilot study, we created a dedicated primary team headed by a senior cardiologist, a general physician, 2 nurses, and an administrator. The cardiologist acts as leader and "gatekeeper" for the entire program, is the primary contact for referring physicians, and is responsible for the financial success of the model. The general physicians and nurses ensure that patients receive appropriate education, and their medical needs are properly prioritized to access the system and undergo diagnostic and/or therapeutic procedures in a timely fashion.

During the first 12 months, the frequency of EOC had to be adjusted as we realized that risk management of the population had not been optimal in the years before the implementation of the model, with more patients requiring diagnostic and therapeutic procedures than previously anticipated. Some of the most significant challenges involved the management of waiting lists due to the identification of patients requiring care during the first year, with 83 patients undergoing a total of 104 cardiac surgical procedures with an overall mortality of $2.4 \%$. The second year, the number of surgical patients decreased to 57 (88 procedures) with mortality dropping to $1.8 \%$, indicating improved risk-management of the population.

The net operating margin at the end of the second year of the exercise was $7.5 \%$ per year as compared with $4.5 \%$ in the first year. The financial success was multifactorial: the primary team's cost was factored into the model from the beginning; no hospital auditors were required, as no auditing was performed by the EPS; billing was simplified by generating a single, unified bill; payments were received on the 15th day of every month, eliminating any financial cost to the hospital; and variability of care through the implementation of integrated care pathways and physician engagement was decreased, which led to lower incidence of complications in the second year (Table 1).

As the model moves into its third year, we have identified a few of aspects that need to be addressed to guarantee its sustainability and widespread adoption:

1. As stated by Engelman, ${ }^{1}$ a measure of severity of disease has to be taken into account to avoid risk aversion by participating institutions. To address this issue, we are

TABLE 1. Operative outcomes

\begin{tabular}{lccr}
\hline \multicolumn{1}{c}{ Variables } & $\mathbf{2 0 1 7}(\mathbf{N}=\mathbf{8 3})$ & $\mathbf{2 0 1 8}(\mathbf{N}=\mathbf{5 7})$ & $\boldsymbol{P}$ value (differences between years) \\
\hline Bleeding requiring reoperation, $\mathrm{n}(\%)$ & $10(12.1)$ & $4(7)$ & .326 \\
Deep wound infection, $\mathrm{n}(\%)$ & 0 & 0 & $.1(1.7)$ \\
Surgical infection, $\mathrm{n}(\%)$ & $2(2.4)$ & $3(5.3)$ & .791 \\
Postoperative AF, n (\%) & $16(19.3)$ & $23(40.3)$ & .017 \\
Transfusion, n (\%) & $27(32.5)$ & $1(1.7)$ & .343 \\
Mortality, n (\%) & $2(2.4)$ & $28(20-72)$ & .791 \\
ICU stay, h, median (IQR) & $35(22-85)$ & $8(5-112)$ & .757 \\
Hospital stay, d, median (IQR) & $9(6-13)$ & .823 \\
\hline
\end{tabular}

$A F$, Atrial fibrillation; $I C U$, intensive care unit; $I Q R$, interquartile range. 
validating the use of Diagnosis-Related Groups, and plan to start applying them to factor in patient acuity.

2. Ongoing implementation of integrated care pathways to decrease variability of care and complications is critical to the success of the program.

Given the results of the model, starting in July 2019, our partner EPS will remove all auditing personnel from our institution and abolish authorization processes for patients included in the model. We will be responsible for the comprehensive care of the patients, including diagnostic procedures and treatments, all of which will be "pre-authorized." The trust generated between these 2 organizations represents a significant paradigm shift, which has led to a substantial improvement in the way we care for our patients. This should decrease costs for the EPS and the health care system.

Alternative payment models implemented in a "topdown" fashion by government agencies, such as the Bundled Payments for Care Improvement Initiative, have gained traction over the past few years. Such proposals have met with push-back from institutions as well as the medical community, as some may see it as a way to transfer the financial responsibility to hospitals and physicians. ${ }^{2}$ Our experience shows that the key to successful implementation of these models is in the interdisciplinary work of expanded teams, much like we have done with the establishment of Heart Teams across the spectrum of care for patients with valvular and coronary artery disease. Only this time, we have to include hospital administration, industry and, most importantly, government and insurance companies. We believe this effort should be led by physicians, as no one else sees the "whole picture" better than us, while keeping the patient's wellbeing at the center of it all.

\section{Conflict of Interest Statement}

Author has nothing to disclose with regard to commercial support.

\section{References}

1. Engelman DT. Surgical economics: MACRA, MIPS, and bundles-lessons learned in the first 3 years of a coronary artery bypass grafting alternative payment model. J Thorac Cardiovasc Surg. 2017;153:381-4.

2. Hawkins RB, Mehaffey JH, Yount KW, Yarboro LT, Fonner C, Kron IL, et al. Coronary artery bypass grafting payment proposal will have significant financial impact on hospitals. J Thorac Cardiovasc Surg. 2018;155:182-8.

3. Koeckert MS, Grossi EA, Vining PF, Abdallah R, Williams MR, Kalkut G, et al. Ninety-day readmissions of bundled valve patients: implications for healthcare policy. Semin Thorac Cardiovasc Surg. 2019;31:32-7.

4. LaPar DJ, Filardo G, Crosby IK, Speir AM, Rich JB, Kron IL, et al. The challenge of achieving $1 \%$ mortality in coronary bypass grafting: a multi-institution Society of Thoracic Surgeons database analysis. J Thorac Cardiovasc Surg. 2014;148:2686-96.

5. Glotzbach JP, Sharma V, Tonna JE, Pettit JB, McKellar SH, Eckhauser AW, et al. Value-driven cardiac surgery: achieving "perfect care" after coronary artery bypass grafting. J Thorac Cardiovasc Surg. 2018;156:1436-48.

6. Organization for Economic Co-Operation and Development. OECD health statistics 2016. Available at: http://www.oecd.org/els/health-systems/health-datahtm. Accessed April 14, 2019.

7. Porter ME. What is value in health care? N Engl J Med. 2010;363:2477-81.

8. The World Bank. Colombia. Available at: http://data.worldbank.org/country/ Colombia. Accessed February 6, 2017.

9. World Health Organization. Global expenditure database. Available at: http:// apps.who.int/nha/database/Home/index/en. Accessed April 14, 2019.

10. Davies J, Mazza O. The pharmaceutical \& healthcare industry in Latin America. Available at: http://citibank.com/transactionservices/home/about_us/online_ academy/docs/JDavis.pdf. Accessed February 16, 2017.

11. The Economist Intelligence Unit. Value Based Healthcare: A global assessment. 2016. Available at: http://vbhcglobalassessment.eiu.com/?country=co. Accessed April 14, 2019. 